University of St. Thomas, Minnesota

UST Research Online

Operations and Supply Chain Management

Faculty Publications

Operations and Supply Chain Management

2010

\title{
A Knowledge Framework Underlying Process Management
}

\author{
Kevin Linderman \\ University of Minnesota - Twin Cities, linde037@umn.edu \\ Roger G. Schroeder \\ University of Minnesota - Twin Cities, rschroed@umn.edu \\ Janine Sanders \\ University of St. Thomas, Minnesota, sand8871@stthomas.edu
}

Follow this and additional works at: https://ir.stthomas.edu/ocbopmtpub

Part of the Business Administration, Management, and Operations Commons, and the Management Sciences and Quantitative Methods Commons

This Article is brought to you for free and open access by the Operations and Supply Chain Management at UST Research Online. It has been accepted for inclusion in Operations and Supply Chain Management Faculty Publications by an authorized administrator of UST Research Online. For more information, please contact asle4660@stthomas.edu. 


\title{
A Knowledge Framework Underlying Process Management*
}

\author{
Kevin Linderman ${ }^{\dagger}$, Roger G. Schroeder, and Janine Sanders \\ Operations and Management Science Department, Carlson School of Management, University \\ of Minnesota, 321 19th Avenue South, Minneapolis, MN 55455, e-mail: linde037@umn.edu, \\ rschroed@umn.edu,sand8871@stthomas.edu
}

\begin{abstract}
Organizations are increasingly implementing process-improvement techniques like Six Sigma, total quality management, lean, and business process re-engineering to improve organizational performance. These techniques are part of a process management system that includes the organizational infrastructure to support the improvement techniques. The knowledge-based view of a firm argues that organizational knowledge is the source of competitive advantage. To the extent that the process management system enables knowledge creation it should be a source of competitive advantage. This study investigates the underlying framework and factors of a process management system that lead to organizational knowledge creation. Prior studies have considered knowledge creation in process improvement, but none have considered the role of the process management system. Specifically, the study uses the case study method to investigate multiple levels (organization level and project level) of two firms using Six Sigma as their chosen process management system. Analysis of the cases reveals that the leadership creates a supportive infrastructure enabling process-improvement techniques to effectively create organizational knowledge. Interestingly, focusing on decision-making tools and methods may not be effective without developing a supportive infrastructure. The proposed framework provides a basis for organizational leaders to think about how to design and implement a process management system to better enable knowledge creation in organizations.
\end{abstract}

Subject Areas: Case study, Knowledge creation, Process Management System, and Six Sigma.

\section{INTRODUCTION}

The management of organizational knowledge has increasingly been identified as a vital source of competitive advantage (Nonaka \& Takeuchi, 1995). Yet, research on how organizations create and manage knowledge is still in its embryonic stages. Some management scholars have argued that organizations need to develop formal systems that will enable knowledge creation (Senge, 1990). Operations management scholars have recognized the importance of knowledge in

\footnotetext{
*This research was generously supported by National Science Fund grant NSF/SES-0080318.

$\dagger$ Corresponding author.
} 
process improvement (Linderman, Schroeder, Zaheer, Liedtke, \& Choo, 2004; Choo, Linderman, \& Schroeder, 2007). However, little research has been done to identify critical elements of a process management system that enables organizational knowledge creation.

A process management system includes the decision-making tools, techniques, and infrastructure for "design, control, improvement, and redesign of processes" (Silver, 2004, p. 274). A formal process management system makes intentional goal-directed improvements to processes. An effective process management system should result in more knowledge creation. To date little research has investigated the elements of a process management system and how they relate to one another to enable knowledge creation. Failure to understand these elements can make implementing the process management system ineffective.

This study investigates the underlying framework and factors of the process management system that lead to knowledge creation. Using the case study method, a multilevel analysis gives insights of the effects of a process management system at both the project and organizational level. The study finds that organizational factors (leadership and supportive infrastructure) enable project level factors (process-improvement techniques) to create knowledge. Thus, examining each level of analysis adds to our understanding of knowledge creation. Prior studies focused on the improvement techniques without fully considering the infrastructure (Linderman et al., 2004; Choo et al., 2007).

The next section reviews the underlying concepts of a process management system and knowledge creation. The following section then discusses the research methods employed including details on the two case studies and eight projects studied. Findings from these cases result in a framework for knowledge creation when using a process management system. Propositions follow from the framework and give direction for future research. Finally, conclusions and limitations of the study are discussed.

\section{THEORY AND LITERATURE REVIEW}

\section{Process Management System}

Hammer (2002, p. 26) defined process management as a "structured approach to performance improvement that centers on careful execution of a company's endto-end business processes. Formally, a business process is an organized group of related activities that work together to create a result of value to the customer." Others have described process management as "the view of an organization as a system of interlinked processes, [that] involve concerted efforts to map, improve, and adhere to organizational processes" (Benner \& Tushman, 2003, p. 238). Historically, there have been many efforts aimed at developing approaches to improve processes. For example, Shewhart, Deming, and Juran were all strong advocates of process improvement (Evans \& Lindsay, 2005). Several recent developments in operations management such as just-in-time, lean, Six Sigma, total quality management (TQM), and business process re-engineering have a process focus (Silver, 2004). Collectively, the decision-making tools, techniques, and supporting infrastructure can be referred to as the process management system. Although the decision-making tools and techniques have been well studied, less attention has 
been paid to the supporting infrastructure. This study examines the process management systems of companies that have adopted Six Sigma tools and techniques. Six Sigma employs a number of advanced decision-making tools and methods. Schroeder, Linderman, Liedtke, and Choo (2008) give a detailed description of Six Sigma.

\section{Knowledge Creation}

Management theory can help us understand how a process management system creates knowledge. In particular, some management scholars have focused on the role of organizational routines in the knowledge creation process (Levitt \& March, 1988; Nelson \& Winter, 1982). Organizational routines can be defined as "repetitive, recognizable patterns of interdependent actions, involving multiple actors" (Feldman \& Pentland, 2003, p. 96). Nelson and Winter (1982, p. 14) view routines as the source of differences between firms: "Organizations with certain routines do better than others, thus their relative importance in the population is augmented over time". Organizational routines establish organization memory (Huber, 1991), and encode organizational capabilities and knowledge (Levitt \& March, 1988; Argote, 1999). Because routines encode organizational knowledge, they are seen as a key component to knowledge creation (Levitt \& March, 1988). Scholars note that routines act not only as a basis of stability, but also a source of change (Feldman \& Pentland, 2003) and competitive advantage (Teece \& Pisano, 1994). Changes in routines can result in organizational adaptation and learning (Cyert \& March, 1963; Nelson \& Winter, 1982). Intentionally improving routines involves learning and knowledge creation (Argote, 1999).

Organizational routines can be described as programs, standard operating procedures, heuristics, or scripts (Cyert \& March, 1963). One can view the concept of process in operations management as analogous to the concept of organizational routines in the management literature. A process management system can be viewed as a meta-routine (that is, routines to change routines) to create improvements (Adler, Goldoftas, \& Levine, 1999). Many organizations often embed formal meta-routines into process-improvement approaches such as TQM, Six Sigma, and lean as a means to generate change. Such practices have been theorized as a mechanism for generating "dynamic capabilities" (Teece \& Pisano, 1994). As a result, a process management system can be viewed as the organizational infrastructure that intentionally monitors and makes changes to organizational routines. This research investigates the underlying factors that support knowledge creation from instituting a process management system. An effective process management system should result in more knowledge creation.

\section{RESARCH METHODS}

This study takes a grounded theory approach which helps generate insights from field-based case data. The grounded theory approach helps explain emergent phenomena where the existing theory is weak or does not appear useful. In this setting, the grounded theory-building approach can help generate novel insights into phenomena not previously considered in prior research (Glaser \& Strauss, 1967). 
The method of triangulation is used to study process management and knowledge creation (Jick, 1979). Triangulation requires collection and analysis of information and data from multiple sources in order to substantiate important findings. If different sources produce similar findings then confidence in the results increases. Our triangulation approach uses information from the numerous interviews conducted in the field, the literature, and a variety of documents collected from companies as described below.

\section{Sampling}

This research employed theoretical sampling to identify data sources (Eisenhardt, 1989; Miles \& Huberman, 1994). To develop a rich understanding of process management systems that utilized Six Sigma as an improvement technique and knowledge creation we studied two corporations, one in manufacturing and the other in service (referred to hereafter as MFG and SRV, respectively). MFG was more advanced in its deployment of a process management system for Six Sigma than SRV. Four Six Sigma projects were selected from each company; two from each company were representative of the best results obtained (referred to as: device optimization, recovery project, data transmission, outsource) and two from each company had more typical results (referred to as: facilities labor, grinder improvement, third party building, accounts receivable). This variation helps ensure differentiation on the conceptual domains under investigation, which helps improve our understanding of knowledge creation rather than selection on a purely random basis. Furthermore, studying two very different companies and several projects should improve the validity of our findings.

Collecting data at both the corporate level and project level allowed the research team to investigate the multilevel effects that the process management system has on knowledge creation. Scholars have noted the importance of studying multilevels to adequately understand organizational phenomena (Sinha \& Van de Ven, 2005). Scholars have also noted the importance of looking at multilevels when investigating organizational routines, "in response to questions about how tasks are accomplished in organizations, people looking from the outside of the routine, such as hierarchical superiors or researchers, at times will be more likely to describe the apparent aspect of the routine, while people engaged in the routine may be more likely to describe what they do" (Feldman \& Pentland, 2003, p. 111). From the perspective of this research, organizational leaders can have a different understanding of a process management system than project improvement team members.

MFG is a large manufacturing company (multibillion dollars of revenue) engaged in the production of electronic components for the computer industry. This company has been using Six Sigma for three years and is very advanced in its application. MFG has almost 3.5\% of its professional workforce (about 350 out of 10,000 full-time professional employees) working as full-time black belt specialists and they have completed over a thousand Six Sigma projects. MFG has documented savings of over $\$ 400$ million from its Six Sigma efforts in the first two years of deployment. 
SRV is a large (billion dollar plus) service company providing computer software services to its customers. It is a well-established business, but has been implementing Six Sigma at a slow pace. A relatively small number of black belts had been trained and only several projects were completed at the time of this study.

In each company we interviewed corporate officers in addition to individuals associated with each of the projects. The corporate officers were generally in charge of Six sigma efforts and were at the vice president or director level. We also interviewed a black belt who had worked on each of the projects and often reported to project champions (operating vice presidents) who were in charge of the particular processes being studied. In all, 22 interviews were conducted each lasting from one to two hours. Additional follow up interviews were conducted with some respondents to get further clarification.

\section{Data Collection}

In each company a series of questions were asked of those individuals interviewed. At the corporate level we asked questions about both Six Sigma and knowledge creation. For the Six Sigma questions we asked about the history of Six Sigma deployment in the company, how the company defined Six Sigma, the approach used, top management support, training, and benefits. Also, for those interviewed, we asked extensive questions about knowledge creation, diffusion, and retention as a result of Six Sigma projects. For example, we asked what knowledge was created by Six Sigma, how the knowledge was created, to what extent the knowledge was radical or incremental and if Six Sigma was not used, might the knowledge have been created anyway? We also asked corporate level interviewees what knowledge was diffused and retained and to explain the supporting infrastructure. The interviews at the project level followed a similar format, starting with a description or origin of the specific project, following with a description of the project team and method used, and finally knowledge that was created, diffused and retained as a result of the project. If the project did not lead to substantial knowledge creation, then the interviewees were asked what conditions would have led to more knowledge creation.

All of the interviews were conducted on a confidential basis, tape recorded after gaining permission, and then transcribed after the meeting. The transcriptions were entered into non-numerical unstructured data indexing searching and theorizing (NUD*IST), a software program that permits analysis and manipulation of qualitative data (Gahan \& Hannibal, 1998). Each transcript was coded according to the key issues discussed by the informants. The codes were subsequently used to extract data and quotations for analysis purposes. In an effort to triangulate our research results we also collected the following types of written materials from each company: training manuals, briefings on Six Sigma, articles, annual reports, story boards, project meeting minutes, presentations, and other documents.

\section{DATA ANALYSIS}

The researchers analyzed the interviews and materials to supplement the responses obtained from the interviewees. This approach reinforced statements made during 
Figure 1: Process management system knowledge framework.

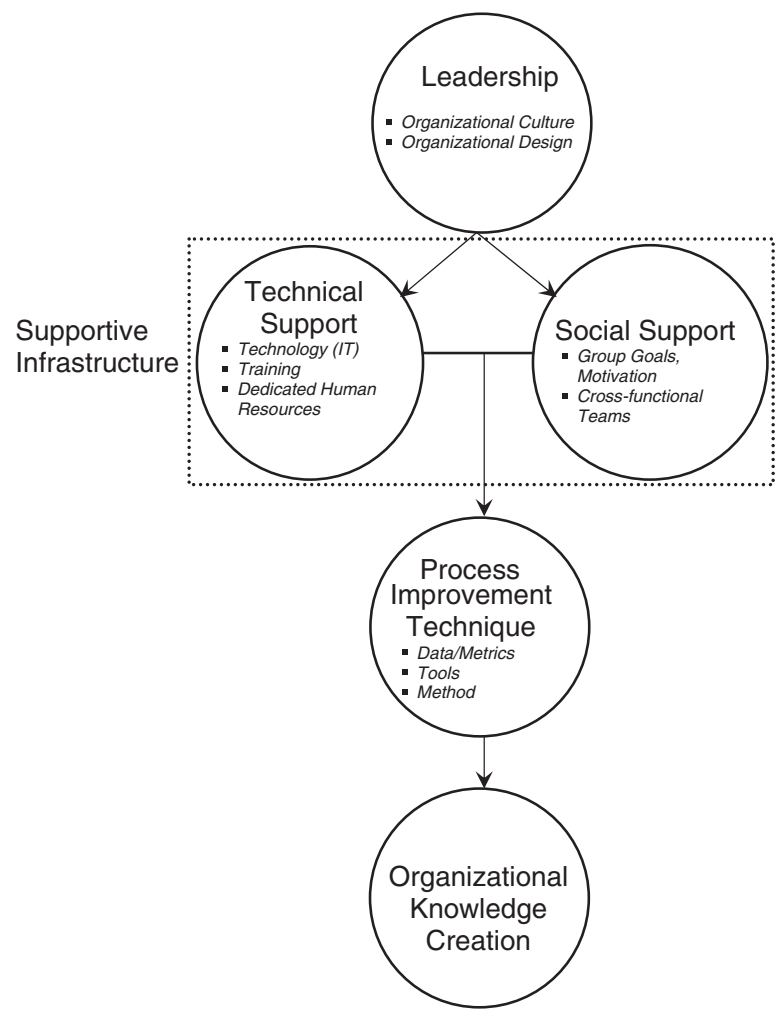

the interviews, or helped identify discrepancies that served as a basis for further inquiry.

In line with qualitative research procedures, the research team first conducted a within-case analysis of each project and each corporation to establish consistency and understanding of the interviews and documents collected. This was followed by a cross-case analysis of the two companies and the eight projects.

For the within-case analysis we conducted a number of meetings to distill the important findings and conclusions from the field data (Eisenhardt, 1989; Miles \& Huberman, 1994; Yin, 1994). Once the within-case analysis was completed, the researchers conducted a cross-case analysis of the two companies and eight projects. Figure 1 summarizes the results. Quotations from the cross-case comparisons are shown in Appendices A through D and the findings are discussed next.

\section{CASE FINDINGS}

A framework of knowledge creation using a process management system emerged from the within and cross-case analyses. This framework consists of four fundamental components that lead to knowledge creation: leadership, technical support, 
social support, and process-improvement techniques. Figure 1 illustrates the arrangement of these four components in a causal model.

\section{Leadership}

Leadership includes setting the vision and designing an organization around process-improvement efforts. An executive at SRV noted the following when reflecting on prior experience where process-improvement efforts failed:

They had done some things-this business had hooked up with a consulting company called XYZ [name changed], which did some basic quality, process improvement kind of things. But it had really died on the vine just because of lack of interest from senior leadership.

Executives from MFG noted the following when reflecting on their deployment of Six Sigma.

The most significant from my point of view is the buy-in of senior executives.... There is a rigor to this deployment that is probably better than the others. There is a top-down engagement to this process.

Numerous studies support the view that leadership matters in times of change (Burke, 2002). Weiner and Mahoney (1981) showed that leadership accounted for $44 \%$ of the variance in profit and $47 \%$ in stock price. Academic research has consistently supported the notion that top management leadership is not only necessary for the process management system, but indeed is the driver of these efforts (Flynn, Schroeder, \& Sakakibara, 1995). Improvement processes should begin with senior management's commitment because they create the organizational systems that design and produce products. This requires transformational leadership (Burns, 1978) that supports learning efforts (Senge, 1990). Vera and Crossan (2004) develop a theoretical model of the impact of CEO and top manager leadership styles and practices on organizational learning. They find that "leadership styles and mechanisms can facilitate and promote the development of stocks and flows of learning" (Vera \& Crossan, 2004, p. 235).

The case analysis reveals that the leadership influence on process management ultimately effects knowledge creation. Two elements of leadership emerged from the case studies that enable knowledge creation-organizational culture and organizational design. Organizational leaders need to establish an organizational culture and design that reinforce one another (Daft, 2000). Appendix A gives a summary of interview data supporting these three factors.

\section{Organizational culture}

An organization's culture, values, and norms influence its ability to learn and make decisions (Senge, 1990; Schein, 1992). Scholars have argued over the importance of having the appropriate culture for conducting process-improvement activities (Detert, Schroeder, \& Muriel, 2000). For example, fact-based decision making is vital to problem solving and root cause analysis (Detert et al., 2000), which contrasts with "gut feel" intuitive decisions (Lortie, 1975). In addition, it is important that the organizational culture has an external orientation as opposed to an internal orientation when making process improvements (Detert et al., 2000). Focusing 
on the customer ensures that an external focus takes place. Leaders discussed the importance of customer satisfaction at MFG and SRV and made explicit use of terminology like CTQ (critical-to-quality), which were attributes of the process critical to the customer. Leaders also helped determine project charters for the Six Sigma projects that explicitly addressed critical customer issues. Creating a focus on the customer gave the organization an external focus which ultimately guided knowledge creation activities. Both MFG and SRV indicated that culture ultimately influenced the improvement teams' ability to create knowledge. MFG and SRV used data and facts along with a customer focus to guide the decision-making process, and provided a supportive climate for knowledge creation (Appendix C). One executive made the following comment about creating the appropriate organizational culture:

The purpose was to build a culture. You isolate it and say okay, here's these few people who are a group that will stick problems in one door and solutions will come out the other, you do nothing to build culture or change the way a company operates. The whole idea here is to train you in method, in a way of thinking and then put you out into the company where you have a spot that can leverage that or affect that.

\section{Organizational design}

Leaders create the organizational systems responsible for production and delivery of goods and services. Scholars have noted the relationship between organizational variables and knowledge creation (Birkinshaw, Nobel, \& Ridderstrale, 2002). Deploying Six Sigma also required making changes to the organizational system to enhance improvement efforts. This involved creating parallel participation structures (parallel organization) "that operate outside of, and do not directly alter, an organization's normal way of operating" (Lawler, 1996, p. 132). Both MFG and SRV developed a parallel organization as part of their Six Sigma deployment. The parallel organization entailed developing specific roles, responsibilities, and structures to engage cross-functions teams in improvement. SRV developed specific roles for champions, black belts, and green belts. Champions sponsored the improvement projects. Black belts led the improvement projects and had more knowledge about the process-improvement methodology and tools. Green belts worked on the improvement projects and usually held more process specific knowledge. MFG had a similar structure with the addition of master black belts, brown belts, and financial belts. In MFG, master black belts trained, supported and mentored champions and black belts. Brown belts were scientists with black belt knowledge and the financial belts validated, verified, and tracked the benefits of the projects. When reflecting on the organizational design one executive noted:

You need to get the organization thinking about itself both horizontally and vertically and as long as you sort of stay in that vertical mentality you don't-so when you process improvement, it cuts across functional lines, obviously, and so you might have a process champion who owns a vertical piece and in order to fix-but what he's actually working on, crosses many boundaries and so they need that overall support. 
MFG had a more advanced design of the parallel organization; they also had a rotation program for black belts. After two years of service in Six Sigma, black belts were required to re-integrate into the organization. The rotation system helped promote knowledge transfer (Song, Almeida, \& Wu, 2003), organizational socialization (Cooper-Thomas \& Anderson, 2002) and cultural change (Kotter and Heskett, 1992). When black belts went back to the regular organization they took with them the process-improvement tools, methods, and values that would often become part of the way they did their work. In general, the parallel organization created more formalization and specialization (Scott, 1987), which enabled process improvement.

\section{Technical Support}

Resources and support structures are required so that systematic improvement can be carried out (Friedman, Lipshitz, \& Overmeer, 2002). Implementing Six Sigma as an organization-wide improvement approach required the development of technical support structures. From our analysis of the interview data, technical support consists of the following three elements: information technology, dedicated human resources, and training (Appendix B).

\section{Information technology}

Both MFG and SRV employed information technology to track and archive improvement projects. One executive noted the importance of project-tracking software that helped track the progress and benefits of improvement projects.

This is specifically a Six Sigma tracking program. It's called PETMET, the Project Excellence Tracking Management Excellence Tracking is what PETMET stands for and every black belt and every champion-the whole black belt and champion structure-gets a copy of this installed on their laptop. ... The first thing that PETMET gives you is the human resources side of your data. And you can update that as you go. The second thing PETMET gives you is project information-and every black belt uses PETMET and this is the methodology that we teach to work on their projects.

The project tracking software provides a knowledge repository for improvement projects. Each step of the improvement process is documented in a storyboard format that gives a learning history of the improvement efforts. Improvement teams search the database for related projects that other teams have already solved or are currently working on. This allows for knowledge storage and transfer in the organization.

Both MFG and SRV reported significant improvements when these systems were utilized. For example, one project at MFG, device optimization, had the highest cost savings of all Six Sigma projects-this project saved over \$36 million dollars. By using PETMET they identified a similar improvement effort occurring at one of their overseas facilities. This led to a cooperative problem-solving effort. These technologies help provide a supportive infrastructure to identify knowledge creation activities throughout the organization. MFG also had policies around technology that further facilitated knowledge creation. For example, before starting a new Six Sigma project black belts were required to check if a similar problem 
had already been solved, and at the end of each week black belts had to upload the status of their projects into PETMET. All the projects studied indicated active use of PETMET, which included searching for similar solutions from other projects and uploading project status so others could see relevant project activities.

SRV also recognized the importance of technology in supporting Six Sigma efforts. However, they were still in the process of developing an information system similar to MFG's to support their Six Sigma efforts. Most of the projects indicated a need for this type of supportive information technology. One project from SRV also indicated that information technology helped extract data necessary to conduct analysis, which further suggests the important role of information technology in problem solving. Without the appropriate information systems in place, data analysis would be impossible. Currently, SRV uses channels such as newsletters and meetings to share knowledge and information about projects.

\section{Dedicated human resources}

Dedicated human resources can be defined as human resources that spend $100 \%$ of their time on projects (Flynn, Flynn, Amundson, \& Schroeder, 1999). Researchers have argued that teams with dedicated human resources can better meet project objectives (Flynn et al., 1999). Dedicated human resources essentially allocate the necessary work capacity to effectively complete project activities, which may not occur when employees work on projects above and beyond their normal responsibilities (Flynn et al., 1999). Both MFG and SRV employ black belts that serve as dedicated human resources to process-improvement projects. These dedicated resources have significant training in techniques of process improvement. They lead project improvement teams and provide expertise in problem-solving techniques and in facilitating team dynamics. By providing dedicated resources, MFG and SRV are able to focus on the technical aspects of knowledge creation.

\section{Training}

A critical component of a process management system is training (Ahire and Dreyfus, 2000). Particularly with Six Sigma, training in roles, methodology, and tools is essential to effective process improvement (Harry \& Schroeder, 1999). The training philosophy and approach was different between MFG and SRV. Both organizations recognized the importance of training, but differed on their approach. In MFG, there was evidence of extensive and differentiated training for all the different belts. In addition, part of the master black belt's role was to teach green belts and train other black belts. In SRV, training sessions were only held for black belts. It was not critical for all team members to be formally trained in Six Sigma and green belts received training during the projects. Training enables team members to learn the technical aspects of process improvement (decisionmaking tools, methods, etc.) but also provides the groundwork for establishing a foundation for social interaction around process improvement.

\section{Social Support}

In contrast to the technical nature, some scholars have noted the social nature of knowledge (Brown \& Duguid, 1991). To know means to be capable of participating 
in the complex web of relationships among people and activities (Brown \& Duguid, 1991). Process improvement often requires traversing different functional boundaries to engage in collaborative problem solving. Using cross-functional teams to solve these problems requires team members to establish a common understanding of the problem and the solution. Six Sigma also employs numerous goals that stimulate organizational members to solve complex problems (Linderman, Schroeder, Zaheer, \& Choo, 2003). The analysis of the interview data identified the following two elements of social support: goals/motivation and cross-functional teams (Appendix C).

\section{Goals/motivation}

In general, goal theory asserts that specific challenging goals lead to higher performance outcomes (Locke \& Latham, 1990). The use of goals in processimprovement teams can have a positive impact on improvement (Linderman et al., 2003). "Goals serve as regulators of human action by motivating the actions of organizational members. Thus, improvement goals motivate organizational members to engage in intentional learning activities that create knowledge and make improvements" (Linderman et al., 2003, pp. 193-194). Both MFG and SRV used specific challenging goals by setting target defects per million opportunities (DPMO) or process Sigma for the improvement project. These goals serve as a guidepost to direct the knowledge creating activities of the team.

\section{Cross-functional teams}

Increasingly, teams are recognized as playing a critical role in knowledge creation. Nonaka (1994) emphasized the importance of socialization where team members create new ideas through dialog and discussion. Cross-functional teams have team members with diverse backgrounds. This forms a "collective mind" (Weick \& Roberts, 1993) around a plurality of perspectives. Effective teams encourage cooperative learning (Johnson, Johnson, Buckman, \& Richards, 1985), which leads to knowledge creation (Janz \& Prasarnphanich, 2003). In MFG and SRV, crossfunctional teams not only included internal people, but at times also included external suppliers and customers. The diversity of team members led to the sharing of ideas and questions from different perspectives. MFG and SRV emphasized the importance of cross-functional teams in creating systems-wide knowledge.

Note from Figure 1 that leadership enables the improvement infrastructure. Scholars (Anderson, Rungtusanatham, \& Schroeder, 1994; Flynn et al., 1995) and practitioners (Deming, 1986) have consistently argued for the importance of leadership in process improvements. The case data reveal the importance of the leader's role in establishing a supportive organizational design and culture to enable the improvement infrastructure, which follows from the selected quotes and proposition.

If you don't have full-time resources, so green belt is supposed to be like 20$25 \%$ of your time on quality, it just doesn't happen. Especially with no senior management engagement, your center structure is get in the push because it becomes my job and oh, yes, you have time for quality do it. (Comments from MFG employee on technical support) 
The CEO needs to establish a data driven culture "I think for example a lot of people operate on gut feel..." (Comments from SRV employee on Social Support)

It is now part of the culture of the company, we still have a need for all our new hires to step in and be able to do the analysis that their boss now expects of them (Comments from MFG employee on social and technical support)

Proposition 1: Leadership that develops a supportive culture (fact-based and customer-focused) and organizational design (parallel and participative) enables social support and technical support.

\section{Social-Technical Support Interaction}

"Organizations consist of diverse subgroups sometimes referred to as 'thought worlds' because they reflect distinct styles of thought" (Fiol, 1995, p. 71). Process improvement projects employ cross-functional teams in problem solving and diagnosis (Ittner \& Larcker, 1997). Bringing cross-functional team members together to solve problems can result in colliding thought-worlds that bring about a breakdown of communication and learning (Bechky, 2003). Establishing a common problem-solving language can help organizational members with dissimilar backgrounds come together and develop a common understanding. Both MFG and SRV emphasized how instituting Six Sigma established a common language and approach to framing and understanding problem solving. For example, one executive when reflecting on how Six Sigma supports improvement efforts noted:

\footnotetext{
Well, what we thought was important is that it [Six Sigma] gives us a common methodology throughout the company. I mean, it's not just to accomplish good results but it's a common methodology for approaching a substantial array of business activities so on the one hand it's a problem-solving mentality, it's a common methodology, it's common language, it's raising the performance level of a great number of individuals. ... And the other part that we liked is that it could be pervasive, it could be used throughout the company not just in manufacturing but engineering, sales marketing, administrative functions. The ability to analyze and solve problems is, of course, an opportunity anywhere in an organization, not just the factory.
}

Scholars have noted that effective dialog can enable a group to develop a shared mindset and overcome cultural barriers and defensive routines (Schein, 1992). By using Six Sigma organizational members from areas such as engineering, manufacturing, and finance had a common language to understand, frame, and solve problems. Dedicated resources and rigorous training help establish a common language that connects the technical and social aspects of process management. Team members involved in improvement projects would use terms like DPMO and process Sigma. As a result, someone from manufacturing might express production problems in terms of a process Sigma while someone from finance would describe the financial implications of operating a process at a specified process Sigma. This technical problem-solving language essentially acts as a universal translator between divergent thought worlds. The technical problem-solving language not only enables social interaction, but also promotes understanding of technical aspects of Six Sigma. 
Figure 1 shows that the interactions between the technical and social perspectives facilitate cross-community problem solving and understanding. Organizations consist of diverse subgroups or communities of practice (Wenger \& Snyder, 2000). Creative breakthroughs can occur when these communities collide (Fiol, 1995). However, this requires developing a common understanding between these diverse views (Bechky, 2003). The same word or phrase-such as customer-requirements-can have different meanings, depending on the person who is interpreting it, based on his or her unique role in the organization. Multiple meanings can occur in organizations from various sources-subcultures, occupations, functions, and networks (Weick, 1995). Instituting Six Sigma creates a common language between organizational members with diverse backgrounds. This enables more social interaction between diverse members to engage in joint problem-solving efforts.

Research indicates that knowledge circulates well within communities of practice (Brown \& Duguid, 1991; Boland \& Tenkasi, 1995), however, knowledge sharing between communities of practice is difficult (Schultze \& Boland, 2000). In particular, the use of information communication technologies has been shown to enable knowledge sharing within communities of practice (Boland \& Tenkasi, 1995), but not between communities of practice (Schultze \& Boland, 2000). Scholars have recognized that reliance on information technology is insufficient for transferring knowledge in this setting (Brown, 1998) because thinking outside one's expertise domain was problematic (Brown, 1998). Similar problems can occur in cross-functional problem-solving teams. Sharing discipline specific knowledge can be difficult in such a setting. In Six Sigma, having dedicated human resources trained in the decision-making tools and methods using a common language (technical support) can promote sharing knowledge across communities of practice and help teams with a data driven culture achieve improvement goals (social support). The result is an interaction between the social and technical core. The technical core creates a common language that allows disparate organizational members to encode ideas from one community of practice and share it with someone from a different community of practice. For example, team members on the Six Sigma projects often used the term DPMO. As a result, someone from finance could discuss the financial impact of a specified DPMO, marketing could talk about the effect of a DPMO level on customers, and operations could discuss process performance in terms of DPMO.

\section{Process-Improvement Techniques}

The process-improvement technique employs numerous decision-making tools and methods (Breyfogle, 1999) to promote rational decision making (Daft, 2000). Consistent with the process-improvement technique, Weick (1995) described process management as a "realist" ontology with a "rationalist" epistemology. That is, process management aims at obtaining a rational understanding of the objective world. This rational approach can be viewed as creating organizational knowledge through formal problem-solving approaches that facilitate rational decision making (Cyert \& March, 1963; Nelson \& Winter, 1982). The process-improvement 
technique consists of the following three elements: data/metrics, tools, and method (Appendix D).

\section{Data/metrics}

"Data is a set of discrete, objective facts about events" (Davenport \& Prusak, 2000, p. 2). Data in and of itself is not knowledge; it offers no judgment or interpretation. However, fact-based decision making would not be possible without data. Data provide the raw material for creating information and knowledge. Knowledge creation occurs by understanding and interpreting data. Both MFG and SRV noted the importance of having data to create knowledge. The use of data helped them move away from decisions based on intuition. It also gave them an objective means to assess project success. With data, before and after effects of changes made to a process could be clearly demonstrated.

"Measurement is the act of quantifying performance dimensions of products, services, processes, and other business activities" (Evans \& Lindsay, 2005, p. 372), which results in data. Metrics refer to the numerical information that results from measurement. Establishing metrics requires careful consideration and establishes a basis for communication (Melnyk, Stewart, \& Swink, 2004). It is a means to identify areas of change and provides evidence of that change. Appropriately establishing and integrating metrics into the organization's performance measurement system can positively affect knowledge creation (Kaplan \& Norton, 2004). Without organizational and project level metrics, it is difficult to be successful at process improvement. MFG and SRV indicated that establishing metrics was a critical success factor and provided the basis for knowledge creation efforts.

\section{Tools}

The Six Sigma methodology uses well-known tools like failure modes and effects analysis, cause-effect charts, and statistical process control (Breyfogle, 1999). Collectively these tools help facilitate problem understanding and resolution. Consider the following comment from SRV.

It's always everybody thinks they understand the problem, but they may understand what the symptoms are but they might not know what the root cause is. So the tools that Six Sigma uses helps you drive down to what's the real cause of an issue.

\section{Method}

Six Sigma employs a common problem-solving method-the centerpiece to the process-improvement technique. The method used depends on whether the task is for process improvement or new product design. In the case of process improvement, the method is patterned after the plan do check act (PDCA) cycle. The method used in MFG was the familiar DMAIC: define, measure, analyze, improve, and control as the five steps in process improvement. A slightly different set of steps called design for Six Sigma is often used for designing or re-designing new products or processes. In MFG these steps are called IDOV: identify, design, optimize, and validate. The method helps reduce risks in decision making and promotes better problem understanding. Consider the following quote from MFG. 
So it's all about risk, this stuff. I mean, you don't need any of these methods. If you have all the time and money in the world and you can afford to screw it up, you can keep trying until you get it right and probably some day you'll get it right. But most organizations don't have that. This is about reducing risk ... So the point is that if you don't follow any methodology and just guess, you might get it right. A lot of risk. The more prescriptive and the more analysis and you've got to break that balance where it's appropriate.

The process-improvement technique is rooted in the organizational rationality literature (Cyert \& March, 1963), where having a formal problem-solving method and tools promotes rational decisions. Cyert and March (1963) emphasize organizational learning as part of decision making, and highlight the role of rules, procedures and routines in order to better adapt to the environment. Both MFG and SRV highlighted the importance of the technical core to promote better understanding and decision making.

Social-technical systems theory argues that "organizational objectives are best met not by the optimization of the technical system and the adaptation of the social system, but by the joint optimization of the technical and social system" (Cherns, 1978, p. 63). Consistent with this view, the case data indicate that both technical support and social support enable the process-improvement techniqueas suggested by the following selected quotes and propositions.

The team always wants to go right to the solution. It's like pulling back a racehorse. But it really works. I really believe in it so I really pushed for it. And they were real pleased with the process. And you have to explain it to them, they have to understand where they're going and how they're going to get there. So I always put together a thing I called the road map and it would say here's what we're going to do and here's how we're going to get there (Comments from MFG employee on Team \& Method)

And that's one of the sub-benefits of six sigma is now you have this fraternity or sorority or collection of people bound together by common training (Comments from MFG employee on Common Language)

Do you think the tools and methods add that much? Or is it more just getting people together and how much do the tools and methods of six sigma add to improvement? Oh, I bet 50\%. If you've got the people there, you've got the commitment, you've got a good problem statement. That's half the job, it's done. And supporting it by analytical data and coming up with what went on there, that's the other half of it, then you can drive the project. You can really drive a project really quickly with that and get good results that you're looking for, definitely. (Comments from SRV employee on combination of social and technical support)

Proposition 2: The interaction between the social support and technical support enables the process-improvement technique.

In all the projects studied, application of the process-improvement technique resulted in changes to organizational processes or organizational routines, which from an organizational routines perspective (Nelson \& Winter, 1982) implies that knowledge creation occurred. The following selected quotes and proposition summarize the effect on the process-improvement techniques and knowledge creation. 
It [process improvement techniques] creates an atmosphere in which decisionmakers ask the right questions. And by asking the right questions and getting the answers to the right questions, they increase their knowledge. (Comments from MFG employee on process-improvement techniques leads to more knowledge)

What they did-well, to kind of qualify that, they came in with a preconceived notion as to what the problem was. It turned out to be something completely different. From a systems solution, that turned out to be different than anybody thought. (Comments from MFG employee on process-improvement techniques leads to more knowledge)

We never spent any time on define. And when we found the low project completion rates. (Comments from SRV employee on poor use of processimprovement techniques results in less knowledge)

Proposition 3: Use of process management techniques results in organizational knowledge creation by changing organizational routines.

\section{CONCLUSIONS}

Organizational processes can be viewed as organizational routines (Becker, 2004) and the intentional improvement to these processes creates organizational knowledge. The knowledge base view of the firm argues that creating organizational knowledge is the basis for creating a sustained competitive advantage (Spender, 1996). This study identifies the factors of a process management system that lead to knowledge creation. Using the context of Six Sigma, we identify several elements that enable knowledge creation. Leadership drives our knowledge creation framework by establishing an organizational design and culture that provides a foundation to the improvement infrastructure. The interaction of technical support and social support then enable the process-improvement techniques. The processimprovement techniques in turn create changes in organizational routines, which result in organizational knowledge creation.

This article provides a first step in understanding the link between process management systems and knowledge creation. Prior studies have empirically looked at how improvement projects lead to project knowledge creation (Choo et al., 2007) or have theoretically argued how various quality practices support knowledge creation (Linderman et al., 2004). However, none of these studies take a comprehensive view of the process management system. We conducted a multilevel case study to get a comprehensive view of how process-improvement decision-making tools, techniques, and infrastructure collectively lead to knowledge creation. The case analyses suggest that practitioners view knowledge creation as changes in organizational routines when improving processes. This requires developing a supportive infrastructure at the organizational level to promote effective changes in organizational routines at the project level.

This model also has implications for practice. For example, practitioners often implement process-improvement practices like Six Sigma with the hopes of creating a competitive advantage. However, some implementations focus primarily on the process-improvement techniques (e.g., DMAIC, tools, and metrics) 
without paying sufficient attention to the infrastructure (social support and technical support). This study argues that implementation is more than applying decisionmaking tools and techniques to improvement projects. Leaders need to develop and support an improvement infrastructure that enables these decision-making tools and techniques. [Received: July 2008. Accepted: June 2010.]

\section{REFERENCES}

Adler, P. S., Goldoftas, B., \& Levine, D. (1999). Flexibility versus efficiency? A case study of model changeovers in the Toyota production system. Organization Science, 10(1), 43-68.

Ahire, S. L., \& Dreyfus, P. (2000). The impact of design management and process management on quality: An empirical investigation. Journal of Operations Management, 18(5), 549-575.

Anderson, J. C., Rungtusanatham, M., \& Schroeder, R. G. (1994). A theory of quality management underlying the Deming management method. Academy of Management Review, 19(3), 472-509.

Argote, L. (1999). Organizational learning. Boston: Kluwer Academic.

Bechky, B. A. (2003). Sharing meaning across occupational communities: The transformation of understanding on a production floor. Organization Science, 14(3), 312-330.

Becker, M. C. (2004). Organizational routines: A review of the literature. Industrial \& Corporate Change, 13(4), 643-677.

Benner, M. J., \& Tushman, M. L. (2003). Exploitation, exploration, and process management: The productivity dilemma revisited. Academy of Management Review, 28(2), 238-256.

Birkinshaw, J., Nobel, R., \& Ridderstrale, J. (2002). Knowledge as a contingency variable: Do the characteristics of knowledge predict organization structure? Organization Science, 13(3), 274-289.

Boland Jr., R. J., \& Tenkasi, R. V. (1995). Perspective making and perspective taking in communities of knowing. Organization Science, 6(4), 350-372.

Breyfogle, F. W. (1999). Implementing six sigma: Smarter solutions using statistical methods. New York: Wiley.

Brown, J. S. (1998). Seeing differently: A role for pioneering research. Research Technology Management, 41(3), 24-33.

Brown, J. S., \& Duguid, P. (1991). Organizational learning and communitiesof-practice: Toward a unified view of working, learning, and innovating. Organization Science, 2(1), 40-57.

Burke, W. W. (2002). Organization change: Theory and practice. Thousand Oaks, CA: Sage.

Burns, J. M. (1978). Leadership. New York: Harper \& Row. 
Cherns, A. (1978). The principles of sociotechnical design. In W. Pasmore \& J. Sherwood (Eds.), Sociotechnical systems: A source book (pp. 61-71). La Jolla, CA: University Associates.

Choo, A. S., Linderman, K., \& Schroeder, R. G. (2007). Method and psychological effects on learning behaviors and knowledge creation in quality improvement projects. Management Science, 53(2), 437-450.

Cooper-Thomas, H., \& Anderson, N. (2002). Newcomer adjustment: The relationship between organizational socialization tactics, information acquisition and attitudes. Journal of Occupational \& Organizational Psychology, 75(4), 423-437.

Cyert, R. M., \& March, J. G. (1963). A behavioral theory of the firm. Englewood, NJ: Prentice-Hall.

Daft, R. (2000). Management (5th ed.). Orlando, FL: The Dryden Press.

Davenport, T. H., \& Prusak, L. (2000). Working knowledge: How organizations manage what they know. Boston: Harvard Business School Press.

Deming, W. E. (1986). Out of the crisis. Cambridge, MA: MIT Press.

Detert, J. R., Schroeder, R. G., \& Muriel, J. (2000). A framework for linking culture and improvement initiatives in organizations. Academy of Management Review, 25(4), 850-863.

Eisenhardt, K. M. (1989). Building theories from case study research. Academy of Management Review, 14(4), 532-550.

Evans, J., \& Lindsay, W. (2005). The management and control of quality. Cincinnati, OH: South-Western.

Feldman, M. S., \& Pentland, B. T. (2003). Reconceptualizing organizational routines as a source of flexibility and change. Administrative Science Quarterly, 48(1), 94-118.

Fiol, C. M. (1995). Thought worlds colliding: The role of contradiction in corporate innovation processes. Entrepreneurship: Theory \& Practice, 19(3), 71-90.

Flynn, B., Flynn, E., Amundson, S., \& Schroeder, R. (1999). Product development speed and quality: A new set of synergies. In M. Stahl (Ed.), Perspectives in total quality (pp. 245-271). Oxford, UK: Blackwell.

Flynn, B. B., Schroeder, R. G., \& Sakakibara, S. (1995). The impact of quality management practices on performance and competitive advantage. Decision Sciences, 26(5), 659-691.

Friedman, V., Lipshitz, R., \& Overmeer, W. (2002). Creating conditions for organizational learning. In M. Dierkes, A. Antal, J. Child, \& I. Nonaka (Eds.), Handbook of organizationl learning and knowledge (pp. 757-774). Oxford, UK: Oxford University Press.

Gahan, C., \& Hannibal, M. (1998). Doing qualitative research using QSR NUD*IST. Thousand Oaks, CA: Sage.

Glaser, B. G., \& Strauss, A. L. (1967). The discovery of grounded theory; strategies for qualitative research. Chicago: Aldine Pub. 
Hammer, M. (2002). Process management and the future of six sigma. MIT Sloan Management Review, 43(2), 26-32.

Harry, M. J., \& Schroeder, R. (1999). Six sigma: The breakthrough management strategy revolutionizing the world's top corporations. New York: Double Day.

Huber, G. P. (1991). Organizational learning: The contributing processes and the literatures. Organization Science, 2(1), 88-115.

Ittner, C. D., \& Larcker, D. F. (1997). The performance effects of process management techniques. Management Science, 43(4), 522-534.

Janz, B. D., \& Prasarnphanich, P. (2003). Understanding the antecedents of effective knowledge management: The importance of a knowledge-centered culture. Decision Sciences, 34(2), 351-384.

Jick, T. D. (1979). Mixing qualitative and quantitative methods: Triangulation in action. Administrative Science Quarterly, 24(4), 602-611.

Johnson, D. W., Johnson, R. T., Buckman, L. A., \& Richards, P. S. (1985). The effect of prolonged implementation of cooperative learning on social support within the classroom. Journal of Psychology, 119(5), 406-412.

Kaplan, R. S., \& Norton, D. P. (2004). Strategy maps: Converting intangible assets into tangible outcomes. Boston: Harvard Business School Press.

Kotter, J., \& Heskett, J. (1992). Corporate culture and performance. New York: Free Press.

Lawler, E. E. (1996). From the ground up: Six principles for building the new logic corporation. San Francisco: Jossey-Bass.

Levitt, B., \& March, J. (1988). Organizational learning. Annual Review of Sociology, 14, 319-340.

Linderman, K., Schroeder, R. G., Zaheer, S., \& Choo, A. S. (2003). Six sigma: A goal-theoretic perspective. Journal of Operations Management, 21(2), 193-203.

Linderman, K., Schroeder, R. G., Zaheer, S., Liedtke, C., \& Choo, A. S. (2004). Integrating quality management practices with knowledge creation processes. Journal of Operations Management, 22(6), 589-607.

Locke, E. A., \& Latham, G. P. (1990). A theory of goal setting \& task performance. Englewood Cliffs, NJ: Prentice Hall.

Lortie, D. C. (1975). Schoolteacher: A sociological study. Chicago: University of Chicago Press.

Melnyk, S. A., Stewart, D. M., Swink, M. (2004). Metrics and performance measurement in operations management: dealing with the metrics maze. Journal of Operations Management, 22(3), 209-218.

Miles, M. B., \& Huberman, A. M. (1994). Qualitative data analysis: An expanded sourcebook (2nd ed.). Thousand Oaks, CA: Sage.

Nelson, R. R., \& Winter, S. G. (1982). An evolutionary theory of economic change. Cambridge, MA: Belknap Press of Harvard University Press. 
Nonaka, I. (1994). A dynamic theory of organizational knowledge creation. Organization Science, 5(1), 14-37.

Nonaka, I., \& Takeuchi, H. (1995). The knowledge-creating company: How Japanese companies create the dynamics of innovation. New York: Oxford University Press.

Schein, E. (1992). Organizational culture and leadership. San Francisco: Wiley.

Schroeder, R. G., Linderman, K., Liedtke, C., \& Choo, A. S. (2008). Six Sigma: Definition and underlying theory. Journal of Operations Management, 26(4), 536-554.

Schultze, U., \& Boland, R. J. (2000). Knowledge management technology and the reproduction of knowledge work practices. Journal of Strategic Information Systems, 9, 193-212.

Scott, W. R. (1987). Organizations: Rational, natural and open systems. Englewood Cliffs, NJ: Prentice-Hall.

Senge, P. M. (1990). The leader's new work: Building learning organizations. Sloan Management Review, 32(1), 7-23.

Silver, E. A. (2004). Process management instead of operations management. Manufacturing \& Service Operations Management, 6(4), 273-279.

Sinha, K. K., \& Van de Ven, A. H. (2005). Designing work within and between organizations. Organization Science, 16(4), 389-408.

Song, J., Almeida, P., \& Wu, G. (2003). Learning-by-hiring: when is mobility more likely to facilitate interfirm knowledge transfer? Management Science, 49(4), 351-365.

Spender, J. (1996). Making knowledge the basis of a dynamic theory of the firm. Strategic Management Journal, 17, 45-62.

Teece, D., \& Pisano, G. (1994). The dynamic capabilities of firms: An introduction. Industrial \& Corporate Change, 3(3), 537-556.

Vera, D., \& Crossan, M. (2004). Strategic leadership and organizational learning. Academy of Management Review, 29(2), 222-240.

Weick, K. E. (1995). Sensemaking in organizations. Thousand Oaks, CA: Sage.

Weick, K. E., \& Roberts, K. H. (1993). Collective mind in organizations: Heedful interrelating on flight decks. Administrative Science Quarterly, 38(3), 357381.

Weiner, N., \& Mahoney, T. A. (1981). A model of corporate performance as a function of environmental, organizational, and leadership influences. Academy of Management Journal, 24(3), 453.

Wenger, E. C., \& Snyder, W. M. (2000). Communities of practice: The organizational frontier. Harvard Business Review, 78(1), 139-145.

Yin, R. K. (1994). Case study research: Design and methods. Thousand Oaks, CA: Sage. 


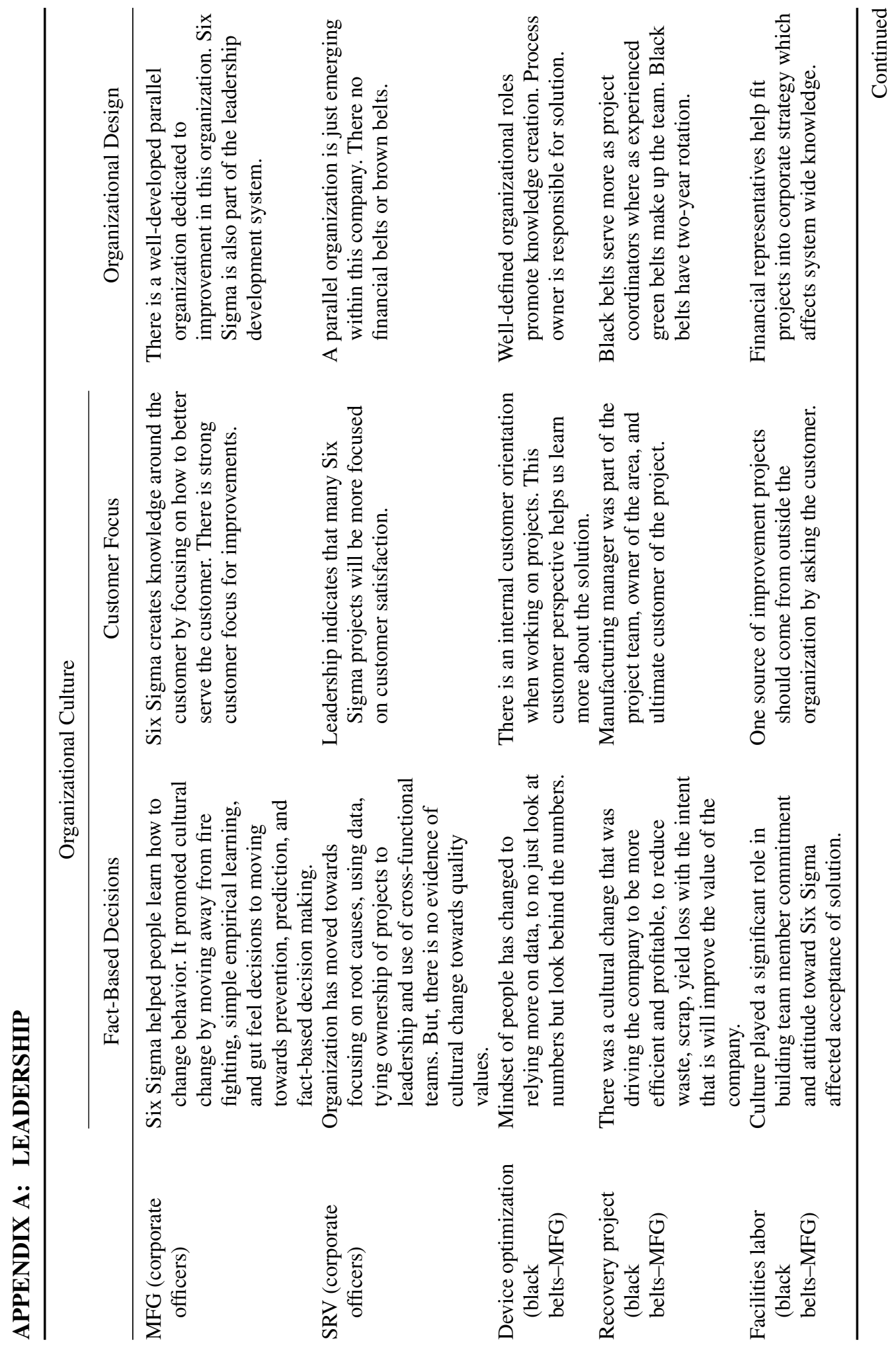




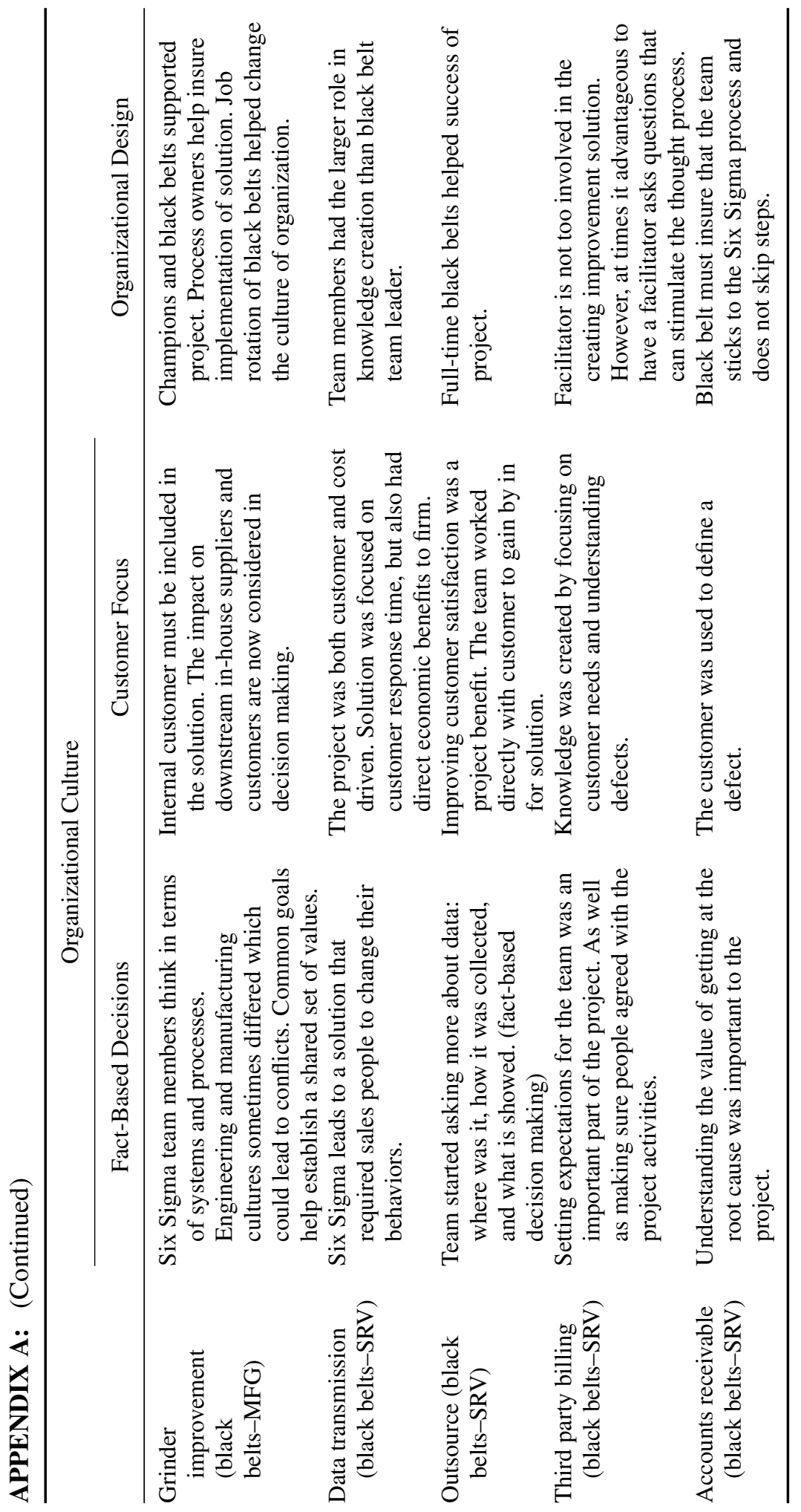




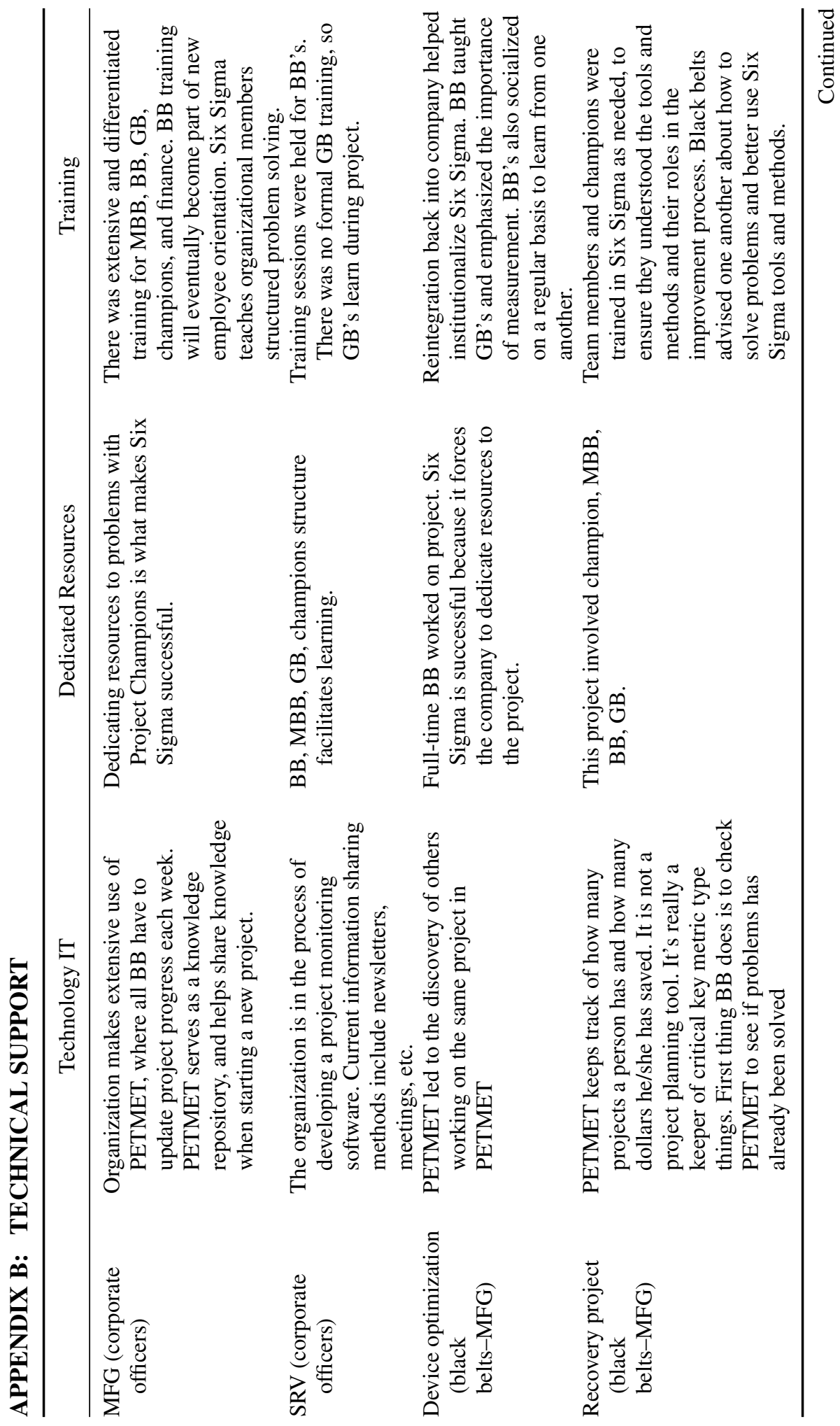




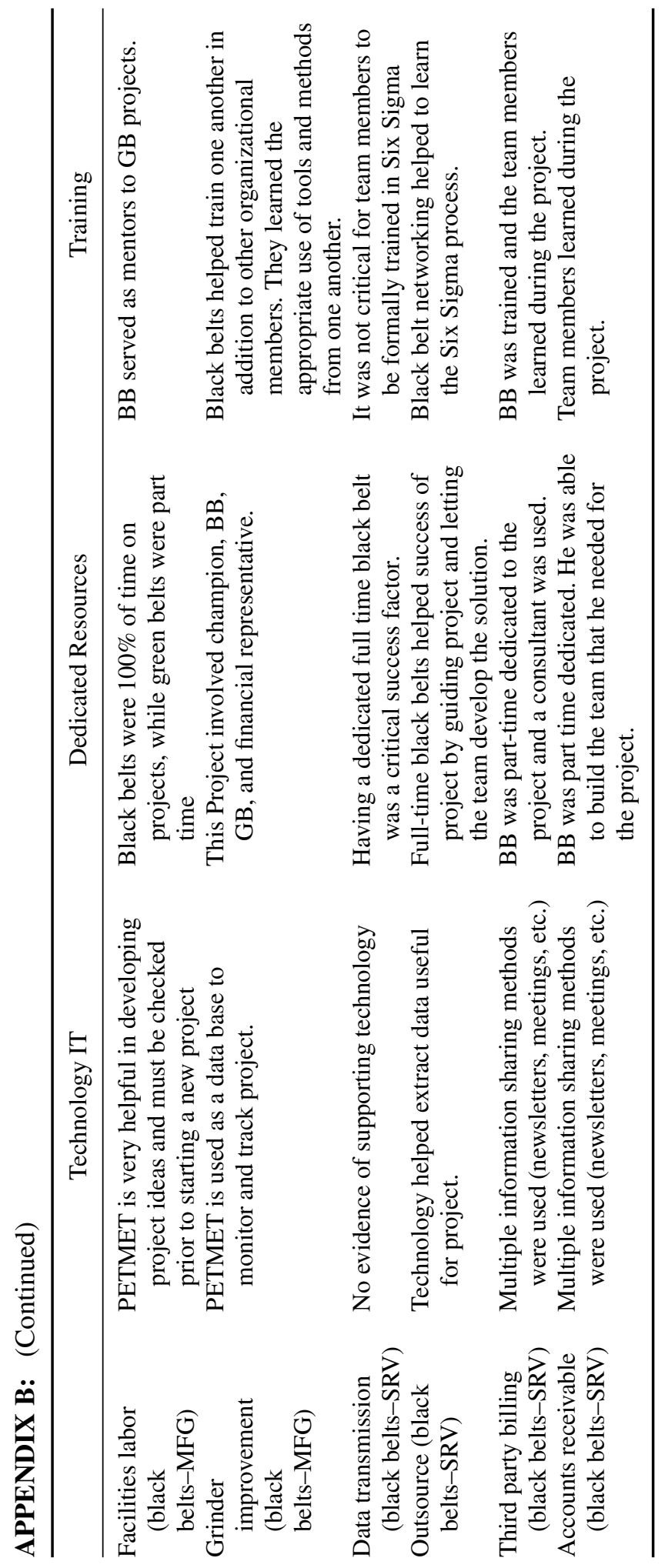




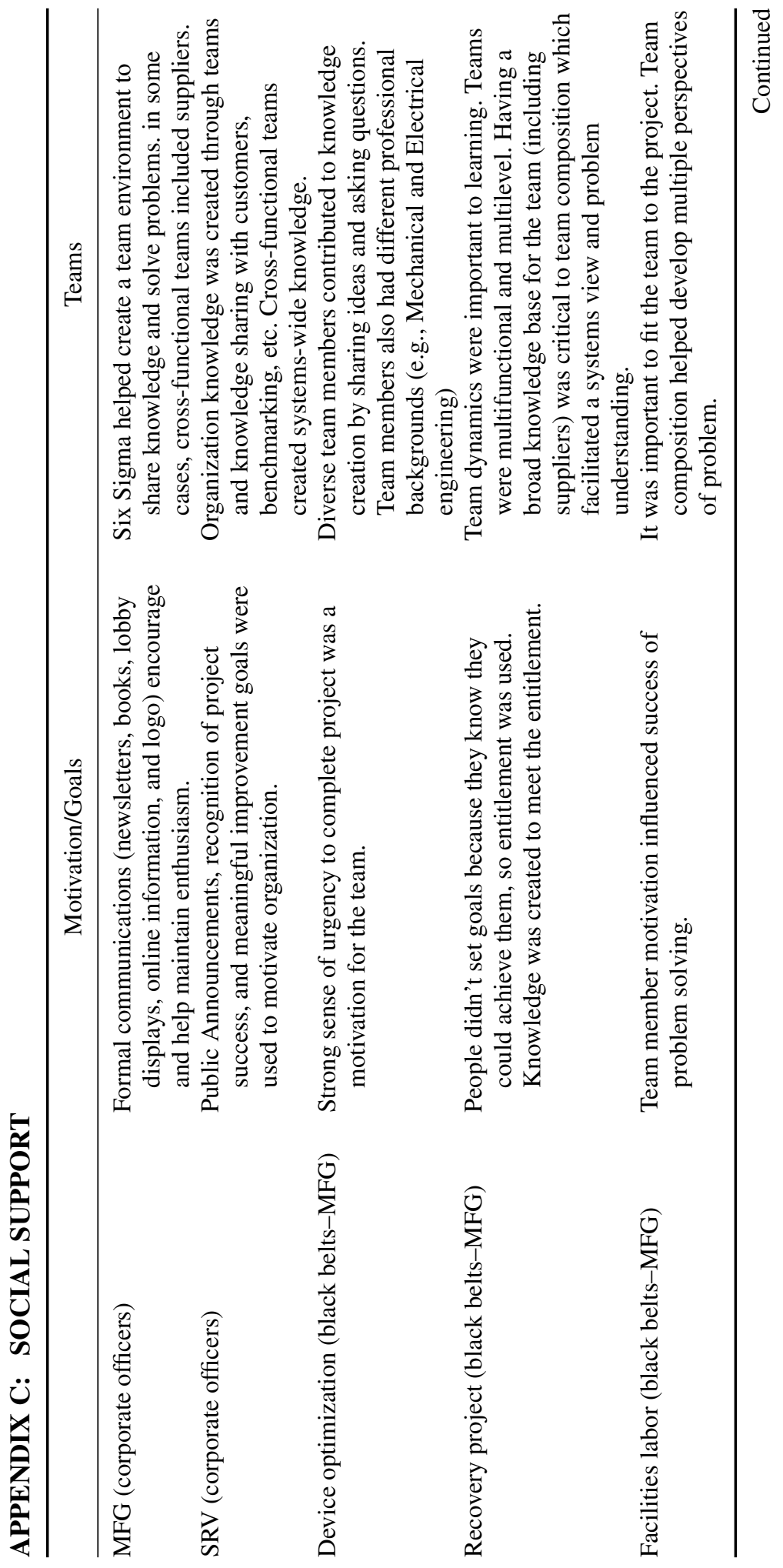




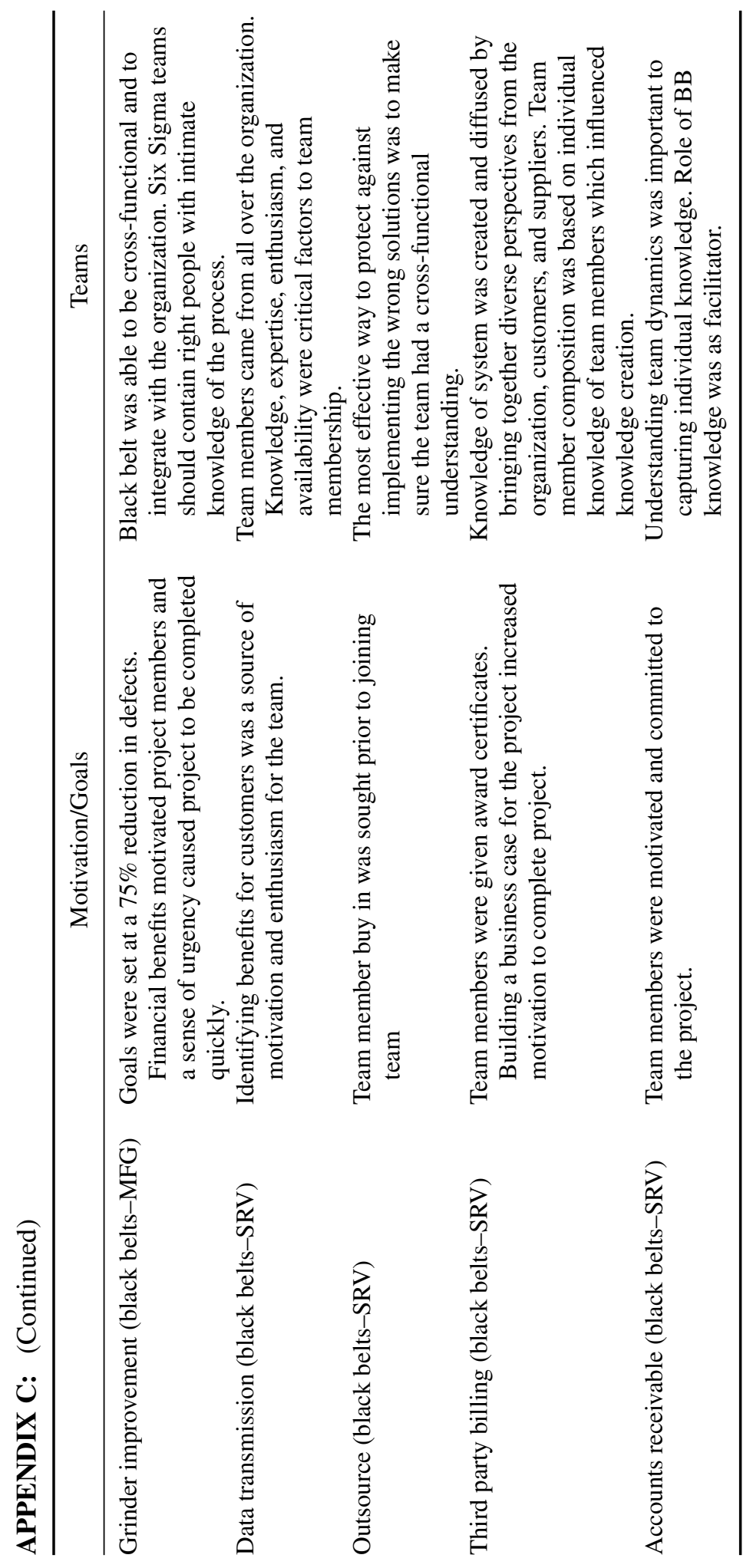




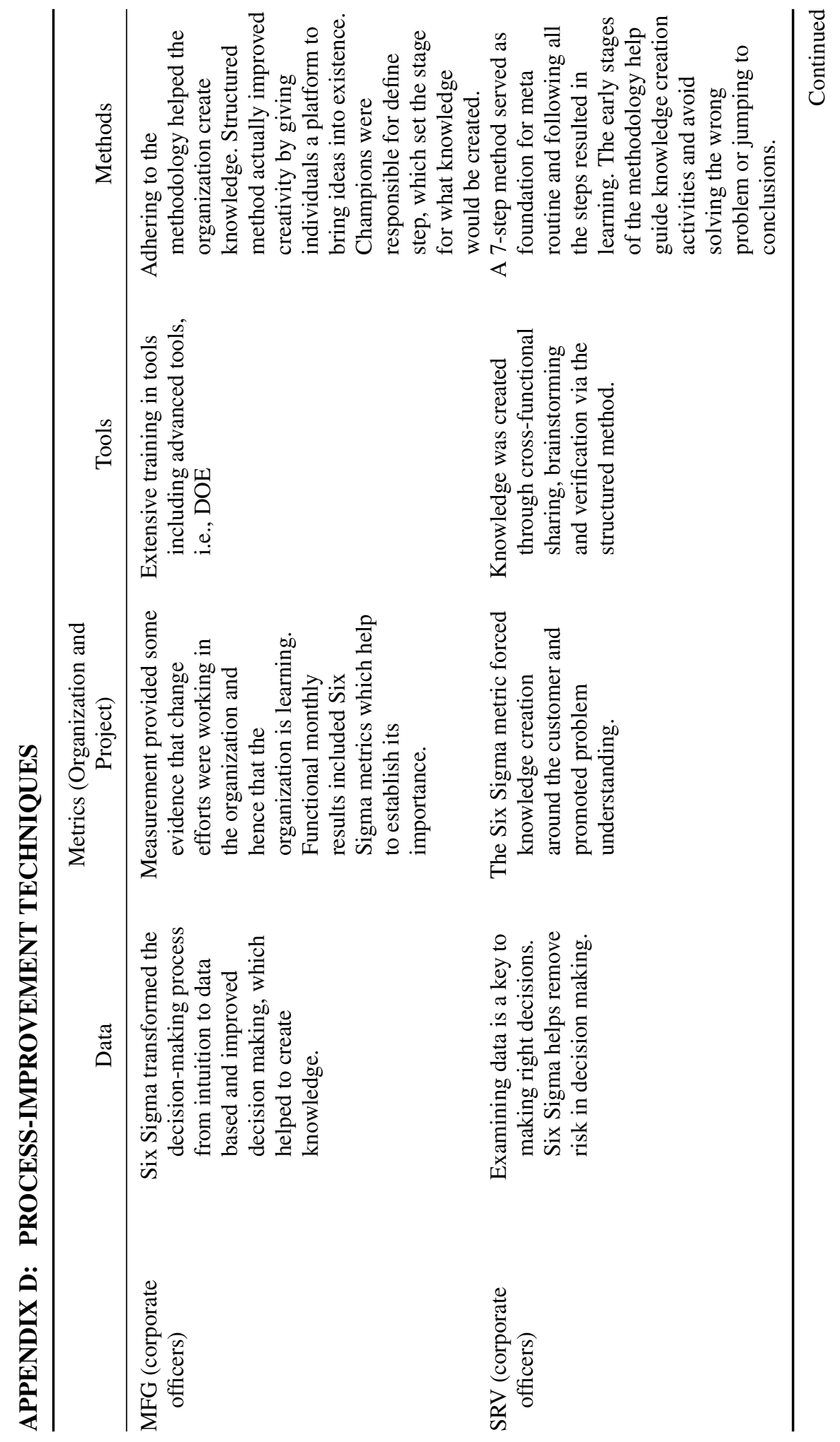




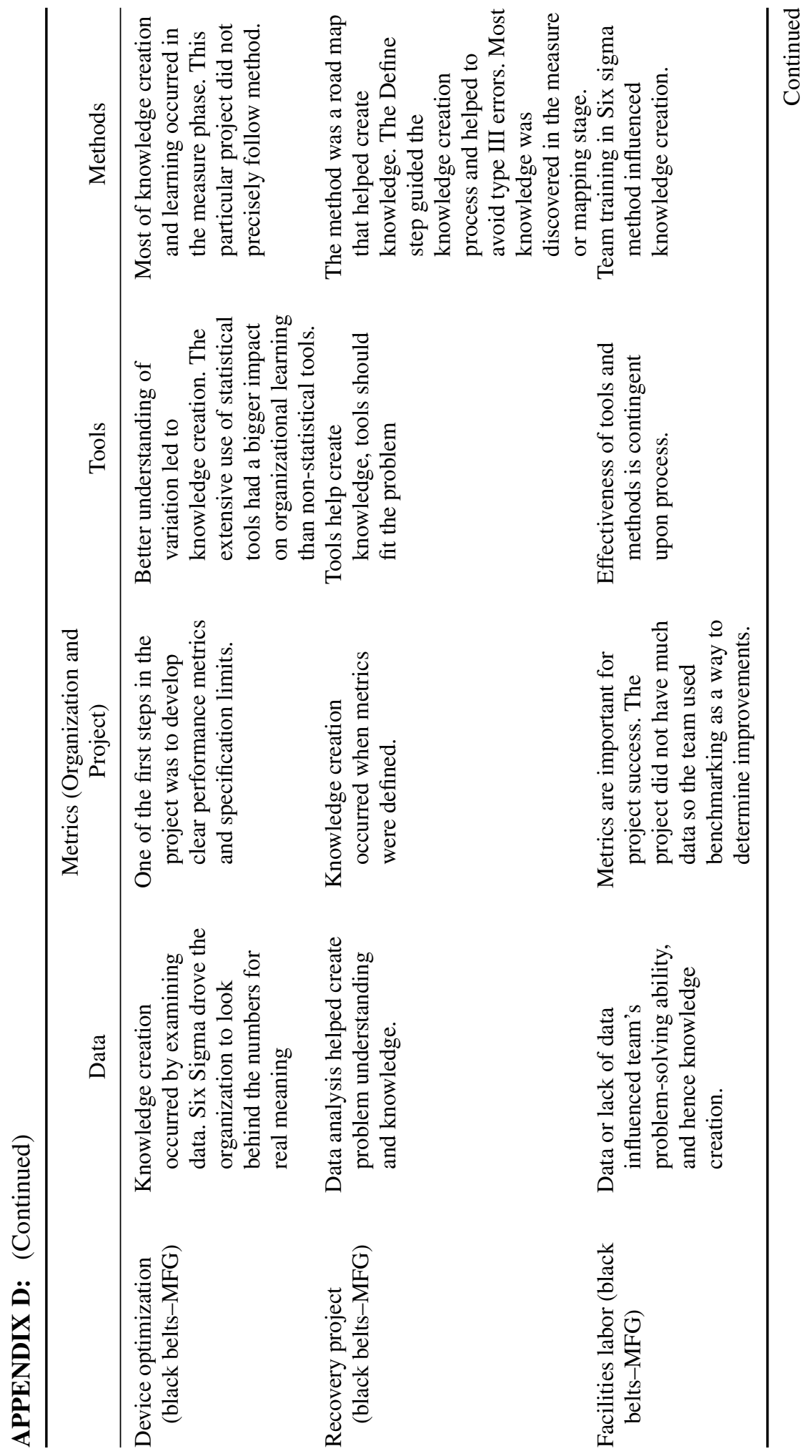




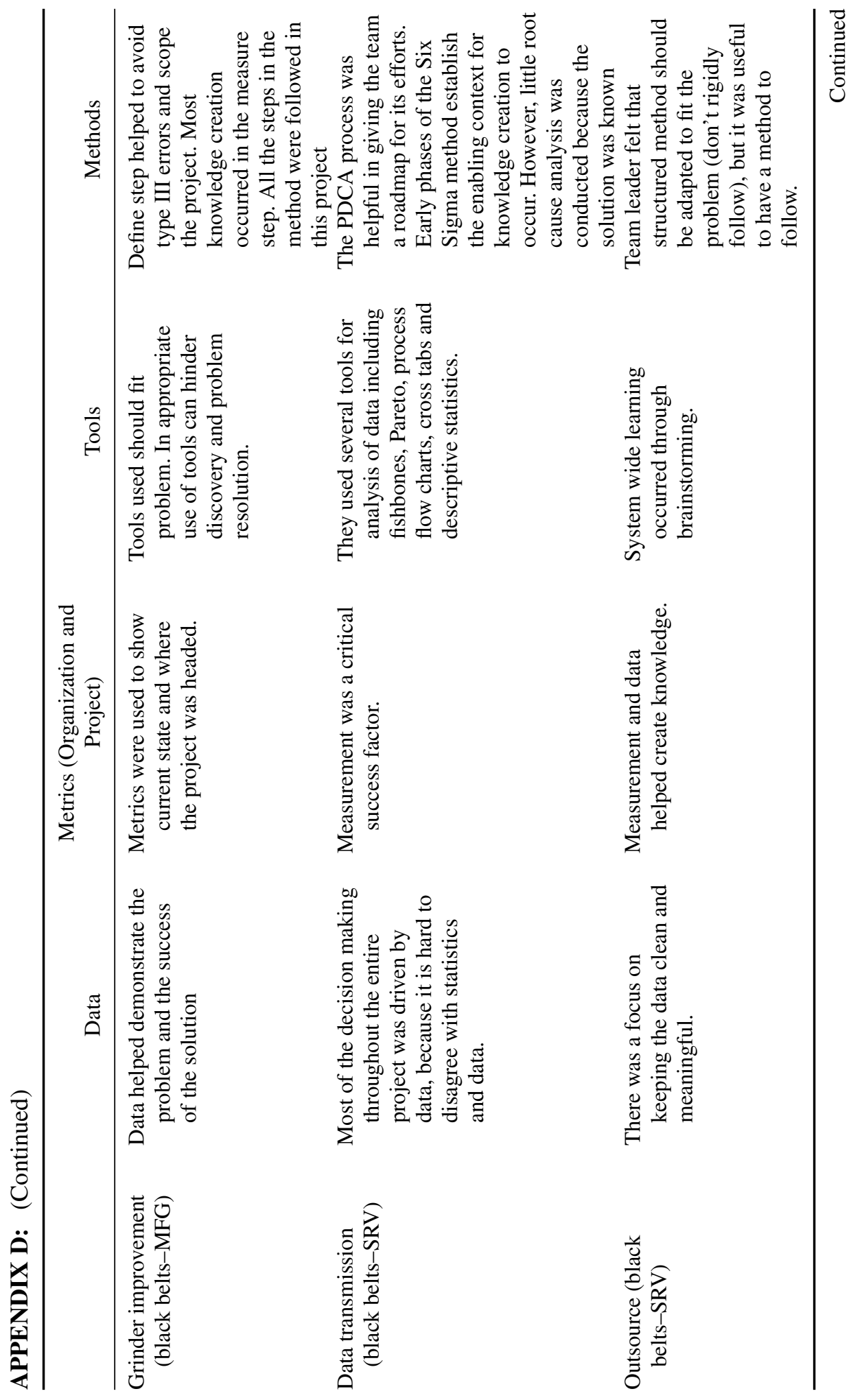




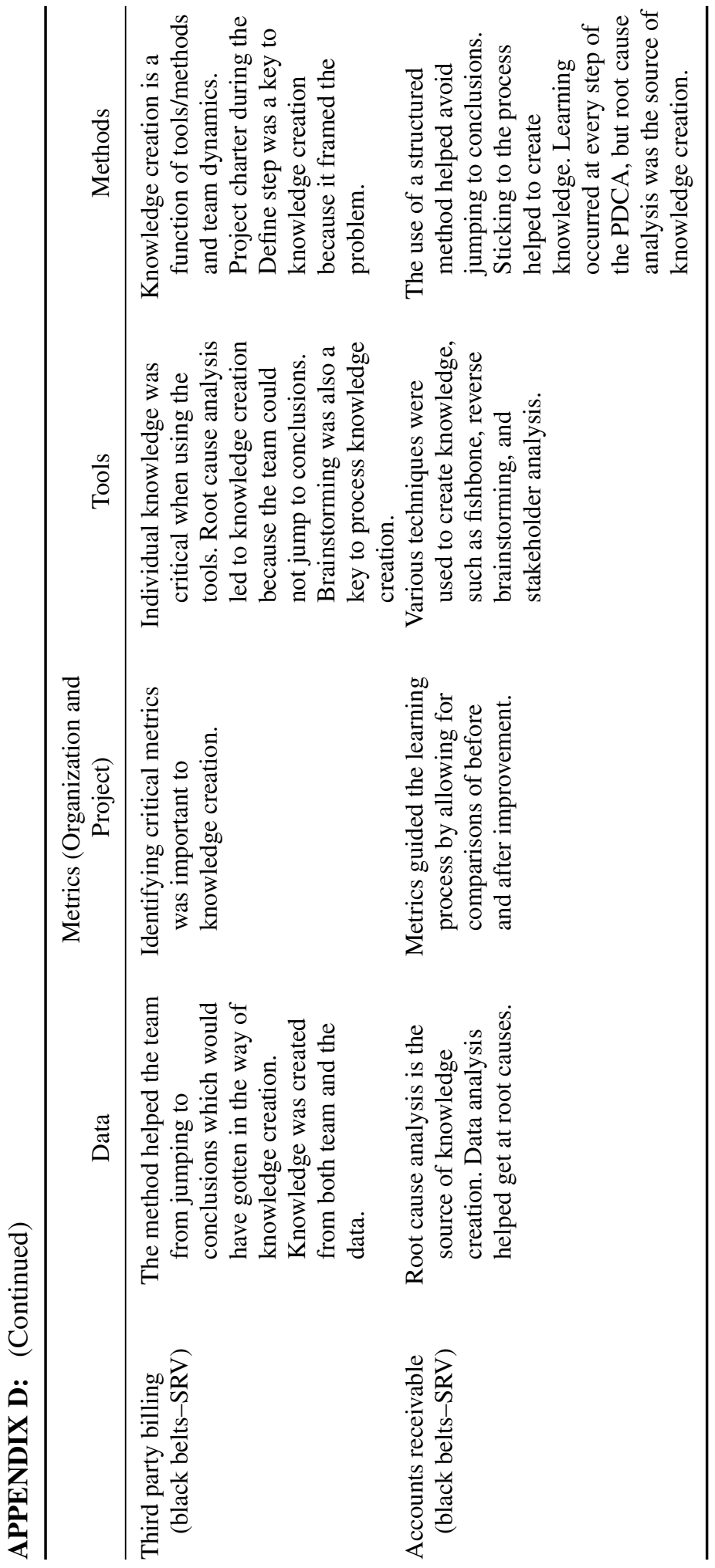


Kevin Linderman is an associate professor at the Carlson School of Management at the University of Minnesota. He has a BA in mathematics and philosophy from Minnesota State University, an MS in mathematics from Miami University, and an $\mathrm{MS}$ and $\mathrm{PhD}$ in operations research and operations management from Case Western Reserve University. His publications have appeared in Management Science, Journal of Operations Management, Production and Operations Management, European Journal of Operations Research, IIE Transactions, Journal of Statistical Computation and Simulation, and Journal of Quality Technology. His research interests include process management and improvement, quality management, six sigma, knowledge management, innovation, and operations management theory.

Roger G. Schroeder holds the Carlson Chair in operations management at the Carlson School of Management, University of Minnesota. He received his PhD from Northwestern University and has publications in major academic journals including Management Science, Journal of Operations Management, Academy of Management Journal, and Production and Operations Management. He is a fellow of the Decision Sciences Institute and of the Production and Operations Management Society. He received the Lifetime Scholarship Achievement Award from the Academy of Management, Operations Management Division, and a Career Research Award from the Carlson School of Management. He has been inducted into the University of Minnesota Academy of Distinguished Teachers.

Janine L. Sanders is an assistant professor in operations and supply chain management at the Opus College of Business at the University of St. Thomas in Minnesota. She holds a BSChE from Ohio University, MSIA from Purdue University, and a $\mathrm{PhD}$ from the University of Minnesota. She worked as an industrial engineer and process engineer before joining academia. Her research interests include quality management, process management, and organization culture. 
This document is a scanned copy of a printed document. No warranty is given about the accuracy of the copy. Users should refer to the original published version of the material. 